\title{
Estimating leaf area index in different types of mature forest stands in Switzerland: a comparison of methods
}

\author{
Anne Thimonier $\cdot$ Isabella Sedivy $\cdot$ Patrick Schleppi
}

Received: 2 January 2009/Revised: 19 November 2009/Accepted: 9 December 2009/Published online: 19 January 2010

(c) Springer-Verlag 2010

\begin{abstract}
Leaf area index (LAI) was estimated at 15 sites in the Swiss Long-Term Forest Ecosystem Research Programme (LWF) in 2004-2005 using two indirect techniques: the LAI-2000 plant canopy analyzer (Licor Inc.) and digital hemispherical photography, applying several exposure settings. Hemispherical photographs of the canopy were analysed using Hemisfer, a software package that offers several new features, which were tested here: (1) automatic thresholding taking the gamma value of the picture into account; (2) implementation of several equations to solve the gapfraction inversion model from which LAI estimates are derived; (3) correction for ground slope effects, and (4) correction for clumped canopies. In seven broadleaved stands in our sample set, LAI was also estimated semidirectly from litterfall. The various equations used to solve the gap-fraction inversion model generated significantly different estimates for the LAI-2000 measurements. In contrast, the same equations applied in Hemisfer did not produce significantly different estimates. The best relationship between the LAI-2000 and the Hemisfer estimates was obtained when the hemispherical photographs were overexposed by one to two stops compared with the exposure setting derived from the reading of a spotmeter in a canopy gap. There was no clear general relationship between the
\end{abstract}

Please contact Patrick Schleppi for further information about the Hemisfer software.

Communicated by R. Matyssek.

A. Thimonier $(\bowtie) \cdot$ I. Sedivy $\cdot$ P. Schleppi

WSL-Swiss Federal Institute for Forest, Snow and Landscape Research, Zürcherstrasse 111, 8903 Birmensdorf, Switzerland e-mail: thimonier@wsl.ch

P. Schleppi

e-mail: schleppi@wsl.ch litterfall and the LAI-2000 or the hemispherical photographs estimates. This was probably due to the heterogeneity of the canopy, or to biased litterfall collection at sites on steep slopes or sites subject to strong winds. This study introduces new arguments into the comparison of the advantages and drawbacks of the LAI-2000 and hemispherical photography in terms of applicability and accuracy.

Keywords LAI - Digital hemispherical photography · LAI-2000 $\cdot$ Litterfall

\section{Introduction}

Leaf area index (LAI), defined as the total one-sided foliage area per unit ground surface area (Chen and Black 1991), is one of the most important characteristics of plant canopy structure. Leaves are the active interface between the atmosphere and the ecosystem. Thus, LAI affects many ecosystem processes, including light and precipitation interception, evapotranspiration, $\mathrm{CO}_{2}$ fluxes and dry deposition. As such, LAI is required as an input variable in most ecosystem process models simulating carbon and water cycles on a stand or regional scale (e.g. Running and Coughlan 1988; Running and Gower 1991).

Direct determination of LAI, however, is time-consuming and labour-intensive, especially with tall and heterogeneous canopies such as those in forests. A number of techniques relying on the radiative transfer theory (Anderson 1971; Ross 1981) have thus been developed to indirectly estimate the LAI of forest canopies. In the most widely applied techniques, LAI is inferred from the inversion of the model describing the attenuation of radiation through the canopy, using gap-fraction data measured 
over a range of zenith angles. Of all the techniques available for measuring gap fractions, the LAI-2000 plant canopy analyzer (Licor Inc., Lincoln, NE, USA) and hemispherical photography are particularly attractive because these sensors can measure the canopy gap fraction from several different zenith angles simultaneously. There has been renewed interest in hemispherical photography, especially since the development of high resolution digital cameras (e.g. Frazer et al. 2001), which allow images to be rapidly processed after acquisition.

A number of studies have compared the LAI estimates obtained with these two indirect techniques with those obtained from direct or semi-direct measurements. LAI estimated with the LAI-2000 usually strongly correlates with LAI measured with litterfall collectors, yet the LAI2000 tends to underestimate LAI (Chason et al. 1991; Cutini et al. 1998; Dufrêne and Bréda 1995; Mussche et al. 2001). The hemispherical photography technique also tends to underestimate LAI (e.g. Chen et al. 1997; Martens et al. 1993; Planchais and Pontailler 1999). The majority of studies comparing hemispherical photographs and the LAI2000 found strong correlations between the LAI estimates obtained with these two techniques (Chen et al. 1997; Coops et al. 2004; Frazer et al. 2000; Macfarlane et al. 2000; Martens et al. 1993).

In this study, we evaluated the LAI-2000 and the hemispherical photography techniques on 15 plots of the Swiss Long-Term Forest Ecosystem Research Programme (LWF, Thimonier et al. 2001) by comparing the LAI estimates with each other, and on seven plots where deciduous trees predominate, with semi-direct estimates of LAI determined from litterfall. Because most of the plots are on more-or-less steep terrain, we were able to test the slope correction method proposed earlier for hemispherical pictures (Schleppi et al. 2007) and apply it to LAI-2000 measurements.

\section{Methods}

Indirect methods: Licor LAI-2000 and hemispherical photographs

\section{Field measurements}

During summer 2004 (30 June-30 August, Table 1), we estimated LAI on 15 LWF plots using two indirect methods: (1) taking hemispherical photographs of the canopy with a digital camera fitted with a fish-eye lens and (2) measuring diffuse radiation below and above the canopy with an LAI-2000 plant canopy analyzer. The LAI-2000 is a portable light sensor system designed to measure diffuse light $(<490 \mathrm{~nm}$, where leaf transmission is low) from several zenith angles simultaneously $\left(0-13^{\circ}, 16-28^{\circ}, 32-\right.$ $43^{\circ}, 47-58^{\circ}$ and $61-74^{\circ}$ ) (Li-Cor 1992).

Both photographs and below-canopy LAI-2000 readings were taken above 16 permanent vegetation quadrats systematically distributed over a $43 \mathrm{~m} \times 43 \mathrm{~m}$ area (intensive monitoring subplot). Measurements were usually carried out either shortly before sunset or under overcast sky conditions. On one plot (VIS; for plot codes, see Table 1), however, the sky conditions were not homogeneous throughout the measurements.

On each vegetation quadrat, photographs of the canopy were taken from $1 \mathrm{~m}$ above ground using a digital camera (Coolpix 4500, Nikon, Tokyo, Japan) with a $183^{\circ}$ fish-eye lens (Nikon FC-E8) fitted to self-levelling gimbals (SLM2, Delta-T Devices, Cambridge, UK) mounted on a tripod. The SLM2 also provides markers for the horizon and the north-south axis. The camera was run in the programme mode where exposure time and focal aperture are set automatically. To prevent camera shake, all pictures were taken with automatic release. The photographs were saved as uncompressed, high resolution files (image size: $2272 \times 1704)$.

In the summer 2005, photographs were taken again above the 16 quadrats on 8 of the plots, this time using several exposure settings instead of the single automatic exposure used in 2004. For each quadrat, the exposure time was first set manually, with the aperture fixed at f/5.3, according to the reading with a spotmeter (Asahi Pentax V, Asahi, Tokyo) in a canopy gap near the zenith. A second and a third photograph were then taken with the exposure increased by one stop and two stops, respectively, by decreasing the shutter speed. A fourth and last photograph was taken in the automatic mode. Between 2004 and 2005, no significant events that could have led to changes in the canopy structure (snow breakage, windthrow, or thinning) had been recorded.

Readings with the LAI-2000 were taken in 2004 above the same quadrats and at the same height as the photographs, usually on the same day and under the same conditions as the photographs, except at OTH. On this latter plot, LAI-2000 measurements were carried out on 30 June 2004, while hemispherical photographs were taken on 30 August 2004. However, we do not expect any differences in the LAI estimates related to the different sampling dates to be significant, as the canopy should be in full leaf at both dates (Holst et al. 2004). The lens was always held levelled, even on plots on slopes, to make the readings comparable to the photographs. Each measure was the average of four readings, taken at positions at most $20 \mathrm{~cm}$ apart from each other. A second LAI-2000 unit, cross-calibrated with the former, was used to automatically take "abovecanopy" readings from a nearby clearing. The measurements were repeated on four of the vegetation quadrats 
Table 1 Description of the sites and dates of measurements

\begin{tabular}{|c|c|c|c|c|c|c|c|c|c|}
\hline Site name & $\begin{array}{l}\text { Site } \\
\text { code }\end{array}$ & Longitude & Latitude & $\begin{array}{l}\text { Altitude } \\
\text { a.s.l. (m) }\end{array}$ & $\begin{array}{l}\text { Mean } \\
\text { slope }(\%)\end{array}$ & Main tree species & $\begin{array}{l}\text { Photographs and } \\
\text { LAI-2000 } \\
\text { measurements }\end{array}$ & $\begin{array}{l}\text { Photographs } \\
\text { in } 2005\end{array}$ & $\begin{array}{l}\text { Litterfall } \\
\text { sampling }\end{array}$ \\
\hline \multicolumn{10}{|l|}{ Coniferous stands } \\
\hline Vordemwald & VOR & $07^{\circ} 53^{\prime} \mathrm{E}$ & $47^{\circ} 17^{\prime} \mathrm{N}$ & 480 & 14 & Abies alba & 06.08 .04 & 25.08 .05 & \\
\hline Alptal & ALP & $08^{\circ} 43^{\prime} \mathrm{E}$ & $47^{\circ} 03^{\prime} \mathrm{N}$ & 1160 & 23 & Picea abies & 03.08 .04 & 28.07 .05 & \\
\hline Chironico & $\mathrm{CHI}$ & $08^{\circ} 49^{\prime} \mathrm{E}$ & $46^{\circ} 27^{\prime} \mathrm{N}$ & 1365 & 35 & Picea abies & 15.08 .04 & - & \\
\hline Celerina & CEL & $09^{\circ} 53^{\prime} \mathrm{E}$ & $46^{\circ} 30^{\prime} \mathrm{N}$ & 1871 & 34 & Pinus cembra & 28.07 .04 & 10.07 .05 & \\
\hline National Park & NAT & $10^{\circ} 14^{\prime} \mathrm{E}$ & $46^{\circ} 40^{\prime} \mathrm{N}$ & 1899 & 11 & Pinus тияо & 29.07 .04 & - & \\
\hline Lens & LEN & $07^{\circ} 26^{\prime} \mathrm{E}$ & $46^{\circ} 16^{\prime} \mathrm{N}$ & 1063 & 75 & Pinus sylvestris & 13.07 .04 & 04.10 .05 & \\
\hline Visp & VIS & $07^{\circ} 52^{\prime} \mathrm{E}$ & $46^{\circ} 18^{\prime} \mathrm{N}$ & 695 & 80 & Pinus sylvestris & 13.07 .04 & - & \\
\hline \multicolumn{10}{|l|}{ Deciduous stands } \\
\hline Jussy & JUS & $06^{\circ} 17^{\prime} \mathrm{E}$ & $46^{\circ} 14^{\prime} \mathrm{N}$ & 501 & 3 & $\begin{array}{l}\text { Quercus robur, } \\
\text { Carpinus betulus }\end{array}$ & 11.07 .04 & - & $24.08 .04-15.11 .04$ \\
\hline Novaggio & $\mathrm{NOV}$ & $08^{\circ} 50^{\prime} \mathrm{E}$ & $46^{\circ} 01^{\prime} \mathrm{N}$ & 950 & 68 & Quercus cerris & 17.08 .04 & 02.08 .05 & $21.09 .04-14.11 .04$ \\
\hline Bettlachstock & BET & $07^{\circ} 25^{\prime} \mathrm{E}$ & $47^{\circ} 14^{\prime} \mathrm{N}$ & 1149 & 66 & Fagus sylvatica & 09.08 .04 & - & $21.09 .04-30.11 .04$ \\
\hline Isone & ISO & $09^{\circ} 01^{\prime} \mathrm{E}$ & $46^{\circ} 08^{\prime} \mathrm{N}$ & 1220 & 58 & Fagus sylvatica & 17.08 .04 & - & - \\
\hline Othmarsingen & OTH & $08^{\circ} 14^{\prime} \mathrm{E}$ & $47^{\circ} 24^{\prime} \mathrm{N}$ & 484 & 27 & Fagus sylvatica & $30.06 .04 / 30.08 .04$ & 23.08 .05 & $30.08 .04-22.12 .04$ \\
\hline Lausanne & LAU & $06^{\circ} 40^{\prime} \mathrm{E}$ & $46^{\circ} 35^{\prime} \mathrm{N}$ & 807 & 7 & Fagus sylvatica & 12.07 .04 & - & 07.09.04-10.01.05 \\
\hline Neunkirch & NEU & $08^{\circ} 32^{\prime} \mathrm{E}$ & $47^{\circ} 41^{\prime} \mathrm{N}$ & 582 & 58 & Fagus sylvatica & 21.07 .04 & 14.07 .05 & $23.08 .04-28.12 .04$ \\
\hline Schanis & $\mathrm{SCH}$ & $09^{\circ} 04^{\prime} \mathrm{E}$ & $47^{\circ} 10^{\prime} \mathrm{N}$ & 733 & 60 & Fagus sylvatica & 22.07 .04 & 10.07 .05 & 08.10.04-07.12.04 \\
\hline
\end{tabular}

after the last quadrat was measured to check the quality of the measurements.

\section{Test of the blooming effect}

Blooming occurs on a digital photograph when light saturation on the sensor spills over onto neighbouring pixels, making canopy gaps appear larger than they really are (Leblanc et al. 2005). This effect was assessed with a grid with 1,250 small round holes, representing $30 \%$ of the area. Pictures of this grid were taken (with the built-in lens) against an overcast sky, through the window of a room in penumbra. In several steps, most of the holes were obstructed, leaving finally only 10 of them open $(0.24 \%$ of the area). Pictures were taken either with an automatic exposure or with the same exposure as the first one (all holes open), and the relative area of holes was measured by counting the light and dark pixels.

\section{Processing of the Licor data}

The methods of Miller and Lang, as well as the ellipsoidal method (see Appendix), are all implemented in the software provided with the LAI-2000 (Li-Cor 1992). The LAI2000 uses 5 values of zenith angle $\theta_{i}$ (averages: $7,23,38$, 53 and $68^{\circ}$ ). However, we restricted the computations to 3 rings only because many of the LWF plots are on hillsides, which meant the soil was visible on the photographs and in the field of view of the LAI-2000. Furthermore, the open areas for the reference readings of the LAI-2000 did not always allow a free $74^{\circ}$ view from the zenith. The fourth ring is theoretically expected to give the best LAI estimate since its field of view encloses the value of $1 \mathrm{rad}\left(57.5^{\circ}\right)$ for which LAI is independent of the leaf angle distribution (Weiss et al. 2004). However, several authors have shown that satisfactory LAI estimates can be obtained by using the 3 internal rings only. Chason et al. (1991) and Dufrêne and Bréda (1995), for example, improved the agreement of the LAI-2000 estimates with independent estimates obtained with direct or semi-direct methods by excluding the fourth and fifth ring from the calculations.

Based on the canopy transmittance calculated for each pair of above- and below-canopy readings, the Li-Cor software estimates LAI according to Miller's (1967) equation as standard output (equations A.3' and A.3" in Appendix). Upon request, the Li-Cor software additionally calculates LAI according to Lang's equation and the ellipsoidal model. Under the assumption of an ellipsoidal leaf angle distribution, LAI is calculated according to the method of Norman and Campbell (1989). The Li-Cor program calculates the mean leaf angle according to Lang and Xiang (1986), using an empirical equation relating the 
slope of the $G(\theta)$ function (see Appendix) to the average foliage inclination angle.

\section{Processing of the hemispherical photographs}

The hemispherical photographs were first transformed into binary black and white pictures using the algorithm of Nobis and Hunziker (2005). This was done either with the Sidelook software they developed at WSL, Birmensdorf, Switzerland (Nobis 2003), or with the same method implemented within Hemisfer. This software, which we also developed at WSL, estimates LAI from hemispherical photographs of the canopy (Schleppi et al. 2007). The optimal threshold to distinguish between sky (white) and canopy (black) is found by searching the picture for borders, which are identified as having the steepest colour gradients between neighbouring pixels in any combination of the red, green and blue channels. In practice, we used the blue channel only, as it potentially discriminates better between blue sky and green vegetation.

In the usual picture file formats, the physical light intensity is coded into brightness values (from 0 to 255) according to a power law, the exponent of which is called $\gamma$ (gamma). For digital still cameras, a typical value of $\gamma$ is 0.45. In Hemisfer, it is also possible to estimate the optimal threshold by applying first the reciprocal power law $(\gamma=2.2)$. Thus, the calculations are performed on the physical light intensity rather than on the computer-coded values. Our hemispherical photographs were analysed separately with and without $\gamma$ transformation, allowing us to estimate its effect on the calculated threshold and LAI.

With Hemisfer, it is also possible to test the various equations that can be applied to solve the inversion model. It calculates the LAI and the leaf angle distribution using (1) Miller's method, implemented here as in the Li-Cor software; (2) Lang's equation; (3) the inversion method with an ellipsoidal leaf angle distribution assumed (see Appendix). Under this assumption, Hemisfer has two outputs: (3a) LAI calculated according to the method of Norman and Campbell (1989), also included in the Li-Cor software; and (3b) LAI estimated by minimizing the sum of squared errors between measured and predicted contact frequencies and by weighting with the solid angle of each ring (Schleppi et al. 2007).

Concentric rings can be superimposed on hemispherical photographs to partition them into zenithal sectors, similar to those obtained with the LAI-2000 optical sensor. In each of the rings, the proportion of visible sky (gap fraction) is then determined to obtain the contact frequency $K(\theta)$. Five rings of $15^{\circ}$ offer the same field of view as the LAI-2000. LAI was calculated for all plots using the three innermost rings only, as with the LAI-2000.
Neither the LAI-2000 nor the hemispherical photography techniques distinguish between light intercepted by foliage and that intercepted by other plant parts (stems, branches, fruits). The LAI estimated with these techniques should therefore be considered a plant or vegetation area index, rather than a leaf area index. Moreover, the inversion model applied to the gap fraction assumes a random spatial distribution of leaves, but this assumption is often not verified. The LAI value obtained from the LAI-2000 and the hemispherical photographs, which figures in equation (A.1), is actually the product of LAI (including woody tissues) and a clumping index $\Omega$, which is determined by the spatial distribution pattern of leaves. This apparent LAI value is referred to as effective LAI by Chen et al. (1991). When the foliage spatial distribution is random, $\Omega$ is unity. When leaves are clumped, which is the case in most plant canopies, $\Omega$ is less than unity. Because the LAI-2000 does not estimate $\Omega$, it was here compared to the hemispherical photographs on the common basis of the contact frequencies $K(\theta)$ and effective LAI obtained.

However, Hemisfer can provide an estimate of the clumping of canopy structures larger than leaves or conifer shoots by implementing the method of Chen and Cihlar (1995), which relies on the statistical analysis of gap sizes measured as sun patches over transects below the canopy. In Hemisfer, concentric circles on the picture are used instead of transects on the site. We determined the clumping indices on the 2004 hemispherical photographs and used them to correct not only the LAI estimates from hemispherical photography but also those obtained with the LAI-2000. These corrected estimates were then compared to those obtained from litterfall sampling.

For the comparison with the LAI derived from litterfall, values estimated from the photographs and from the LAI-2000 were also corrected to take into account the effect of the ground slope. On a slope, if the sensor is set horizontally, light travels a shorter way through the canopy when coming from downhill than it does coming from uphill. Light transmission (in equation A.2) must then be described by the angle of incidence rather than the zenith angle. The LAI obtained from the photographs can be corrected directly in Hemisfer through the implementation of an algorithm described in Schleppi et al. (2007). With the LAI-2000, however, the effect of the slope cannot be estimated directly from the measurements. Therefore, we generated artificial pictures of different slopes, LAI values and leaf angles, as described in Schleppi et al. (2007). Then, we analysed these artificial pictures with Hemisfer and determined iteratively which slope-corrected values corresponded to the noncorrected measurements originally obtained with the LAI-2000. 
Semi-direct method: litterfall collection

On plots with broadleaved species as the main tree species, LAI can be estimated directly from litterfall. The litterfall method theoretically provides the most reliable LAI estimates, which can then be compared with indirect estimates of LAI obtained from the LAI-2000 and hemispherical photographs for validation.

\section{Field sampling}

During the leaf-fall period of 2004, litterfall was sampled on 7 of the 15 LWF plots (Table 1): JUS and NOV (oak stands, Quercus sp.), BET, LAU, NEU, OTH and SCH (beech stands, Fagus sylvatica L.). On each plot, ten circular litterfall traps were installed on two $43 \mathrm{~m} \times 43 \mathrm{~m}$ subplots: five in the intensive monitoring subplot, where the 16 permanent vegetation quadrats are also located, and five in a mirror subplot. Each trap consisted of a ring with a $0.25 \mathrm{~m}^{2}$ collecting area, below which a net in polyester (mesh size $0.25 \mathrm{~mm}$ ) was fixed. The traps were installed horizontally on three wooden stakes $1 \mathrm{~m}$ above ground. They were emptied every four weeks, from the end of August until the end of November or December, when no significant litterfall any longer occurred. The samples were oven-dried $\left(65^{\circ} \mathrm{C}\right)$ to a constant weight upon arrival in the laboratory.

\section{Processing in the laboratory}

The leaves of the litterfall samples were sorted by tree species (main tree species and other species) and weighed per trap and sampling period. The leaves from all sampling periods were then merged per plot and tree species category. A subsample of 500 leaves was subsequently randomly selected from each composite sample. The selected leaves were soaked in water overnight and then left in a plant press for 1-2 days. The leaf area was measured with a leaf area meter (Delta-T Devices Ltd., Burwell, UK) on leaves while they were still humid, to avoid shrinkage. The leaves measured in this way were finally oven-dried again at $65^{\circ} \mathrm{C}$ to a constant weight. The leaf area per unit of dry mass (specific leaf area, SLA) was determined as the ratio between the cumulative area and the cumulative mass of the 500 leaves. LAI was estimated by multiplying SLA by the cumulative dry leaf mass per unit ground area, first using all traps, and then using only the traps located in the intensive monitoring subplot where the LAI-2000 measurements were made and hemispherical photographs taken. At JUS, we also estimated the contribution to the total LAI made by Carpinus betulus L. seeds, which have well-developed leafy bracts.

\section{Results}

Indirect methods

In the following, all reported LAI values were estimated using a field of view of $45^{\circ}$ zenith angle, corresponding to the three innermost rings of the LAI-2000. The LAI estimates obtained from the LAI-2000 are denoted L2000 and those from hemispherical photographs analysed with Hemisfer Lhs. The model applied within each method is then given in subscript: Miller for Miller's equation as implemented in the LAI-2000 (i.e. with extrapolation of the external ring up to the horizon, by transferring the weight of the missing angles to this single ring), Lang for Lang's equation, N\&C for Campbell's ellipsoidal model solved according to Norman and Campbell (1989), and ELAD for the same model but solved according to Schleppi et al. (2007).

Some of the 2005 photographs taken in the manual mode according to the spotmeter reading $(\mathrm{M})$ were quite dark, as were some of those taken with the manual exposure incremented by one stop compared to the spotmeter reading $(M+1)$. In some cases, the thresholding step could not satisfactorily discriminate between sky and foliage, and part of the sky was transformed into black pixels. In contrast, almost all the photographs taken with the manual exposure increased by two stops $(M+2)$ could be thresholded successfully. The comparisons shown in the following (between $\gamma$ values or between calculation models) were therefore performed on the $\mathrm{M}+2$ photographs.

\section{Influence of the $\gamma$ transformation on LAI derived from hemispherical photographs}

LAI estimates derived from photographs thresholded with a $\gamma$ value of 2.2 were, as could be expected, significantly higher than LAI estimates obtained without $\gamma$ transformation $(\gamma=1.0)$. Using a $\gamma$ value of 2.2 resulted in threshold values approx. 30 units higher (median value) than the threshold values obtained with a $\gamma$ value of 1.0. Taking the 2005 photographs with exposure $\mathrm{M}+2$ as an example (Fig. 1), the relative difference for LAI amounted to $12 \%$. Moreover, an interaction with the plot was apparent, with a stronger influence of the $\gamma$ correction at NOV. In the following, all the LAI values derived from hemispherical photographs were obtained with a $\gamma$ value of 2.2.

\section{Comparison of the hemispherical photographs taken} in automatic mode in 2004 and 2005

LAI values calculated from the 2004 and 2005 photographs taken in automatic mode (P) were highly correlated (Fig. 2). However, there were several outliers in the 


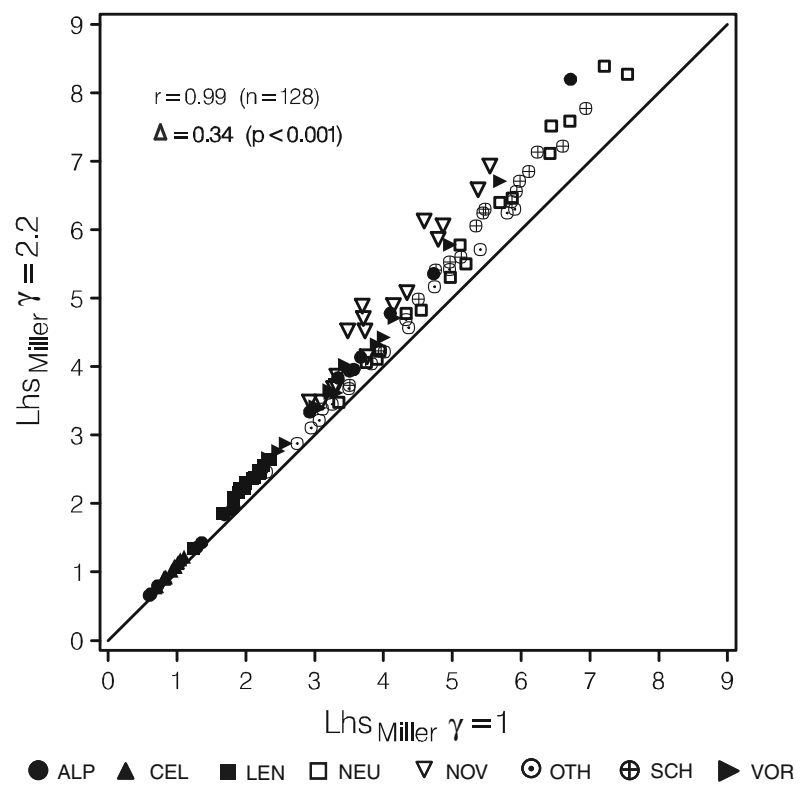

Fig. 1 Influence of $\gamma$ on LAI estimates derived from the 2005 hemispherical photographs (exposure M +2 ) using Miller's equation in Hemisfer (8 plots-filled symbols: coniferous stands-open symbols: deciduous stands)

relationship. Some of them could be attributed to occasional slight shifts in the positions of measurement between 2004 and 2005 (e.g. ALP, quadrat B3). Others were ascribed to light conditions during the measurements. In 2005, at NEU, the quadrats D1-D4 were measured under dark conditions, half an hour after sunset, and the photographs were darker than in 2004.

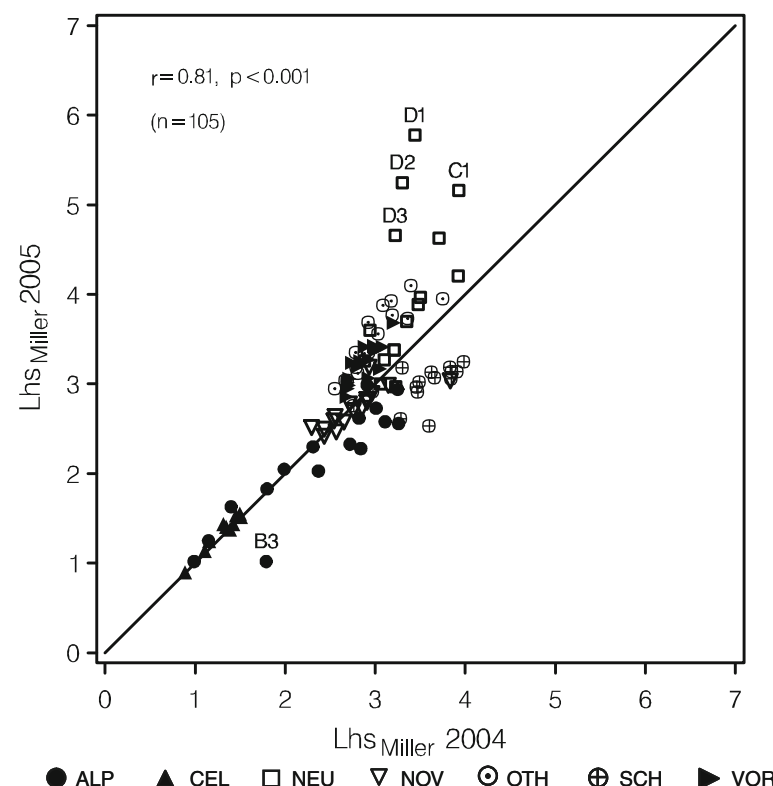

Fig. 2 LAI values calculated from the 2004 and 2005 photographs taken in automatic mode $(\mathrm{P})$, using Miller's equation in Hemisfer (7 plots-filled symbols: coniferous stands-open symbols: deciduous stands)
Moreover, there were systematic differences for some of the plots, e.g. at OTH and VOR (Lhs in $2005>\mathrm{Lhs}$ in 2004) or SCH (Lhs in $2005<$ Lhs in 2004), which might be due to contrasting sky conditions during the 2004 and 2005 field campaigns, although differences due to temporal changes cannot be excluded.

\section{Influence of the exposure in 2005}

Varying exposures resulted in substantial variations in LAI values. Fig. 3 shows the mean LAI per plot and the associated standard error obtained from hemispherical photographs processed with Hemisfer with Miller's equation. The highest LAI values (up to 9 at the beech plot of SCH) were obtained with the $\mathrm{M}$ setting. Differences between the $M+1$ and $M$ exposure settings ranged from -0.1 (plot with the lowest LAI, CEL) to -1.9 (plot with the highest LAI, SCH). By increasing the exposure by one more stop $(\mathrm{M}+2)$, LAI decreased again by -0.2 to -1.1 . The automatic exposure $\mathrm{P}$ corresponded to the $\mathrm{M}$ exposure increased by 3 to 6 stops $(\mathrm{P} \approx \mathrm{M}+3$ at ALP, OTH, VOR; $\mathrm{P} \approx \mathrm{M}+6$ at $\mathrm{SCH}$ ) and resulted in LAI values all below 4. One exception is the open pine stand of CEL, where the automatic exposure $\mathrm{P}$ matched the manual exposure M.

\section{Influence of the calculation method}

With each technique (LAI-2000 or photograph analysed with Hemisfer), the LAI values estimated according to the different models closely correlated with each other (Fig. 4). In the case of the LAI-2000, however, the difference between two estimates derived from two different equations

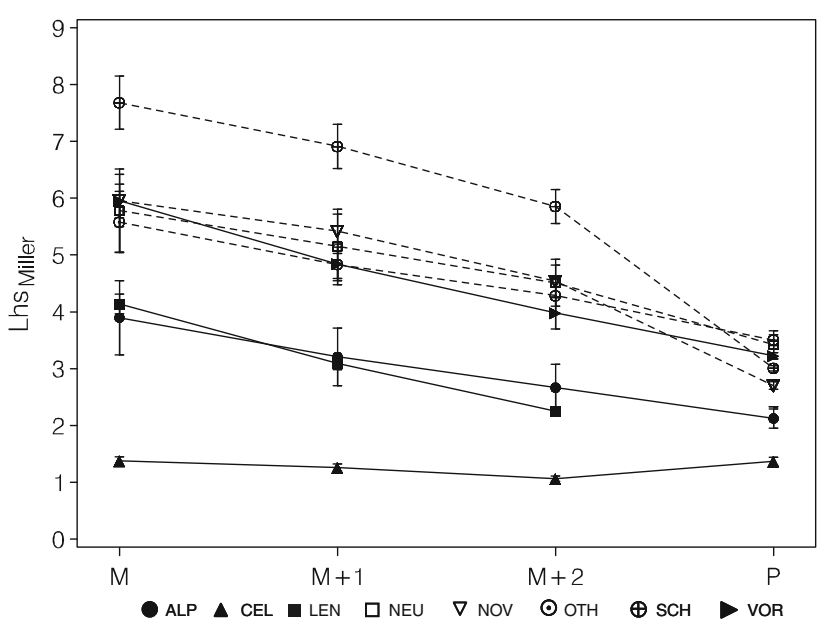

Fig. 3 Influence of exposure on LAI estimates derived from the 2005 hemispherical photographs using Miller's equation in Hemisfer ( 8 plots-filled symbols: coniferous stands-open symbols: deciduous stands) 
(a)
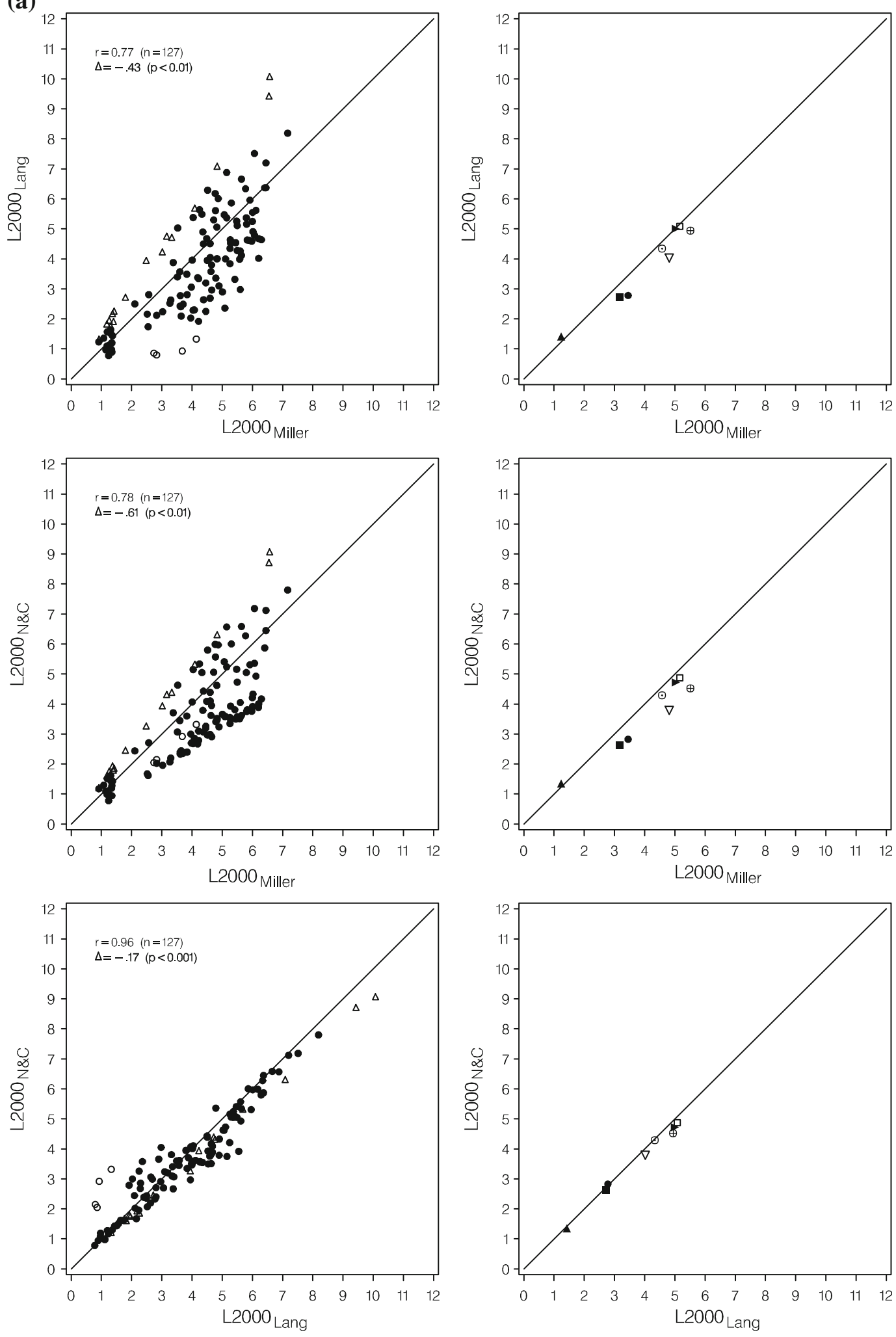

Leaf angle (left)

angle -0

$0<$ angle $<90$

$\triangle$ angle $=90$

Site (right)

ALP $\triangle \mathrm{CEL}$

LEN

$\square$ NEU $\quad \nabla$ NOV $\odot$ OTH $\oplus \mathrm{SCH}$

VOR

Fig. 4 Comparison of model equations with the same technique used. On the left: LAI per quadrat, symbol = leaf angle; on the right: mean LAI per site, symbol $=$ site. a LAI-2000. b and $\mathbf{c}$ Hemispherical photographs $(2005$, exposure $\mathbf{M}+2)$ analysed with Hemisfer $(\gamma=2.2)$ 
(b)
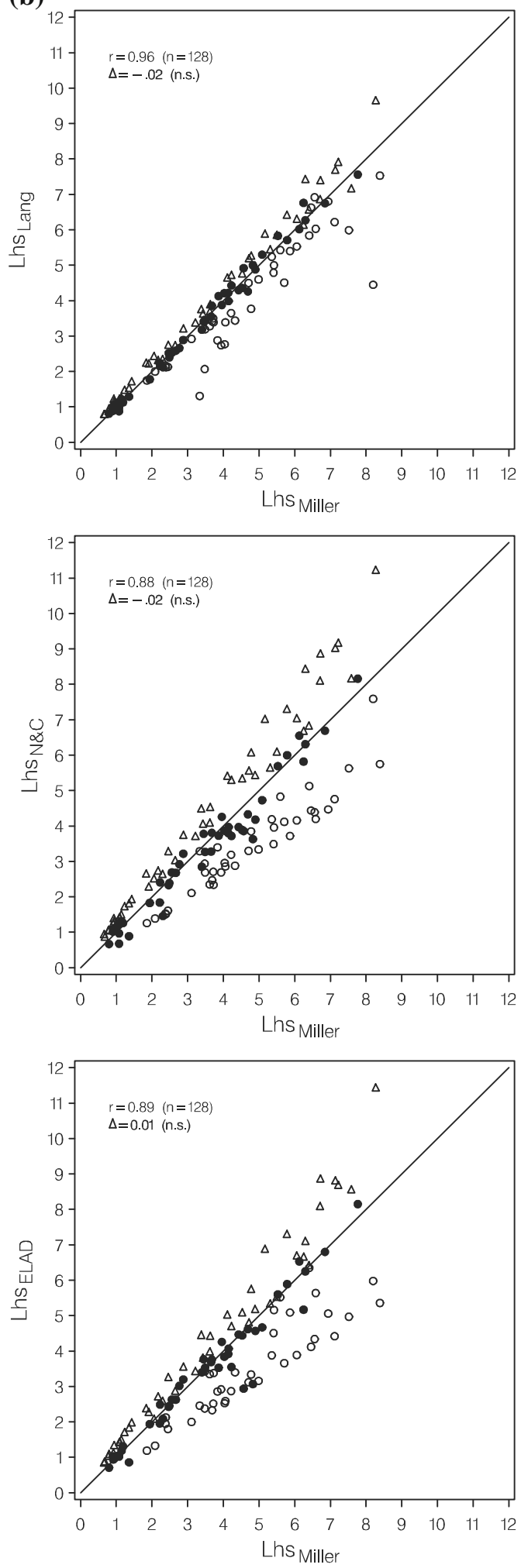

Leaf angle (left)

Site (right)
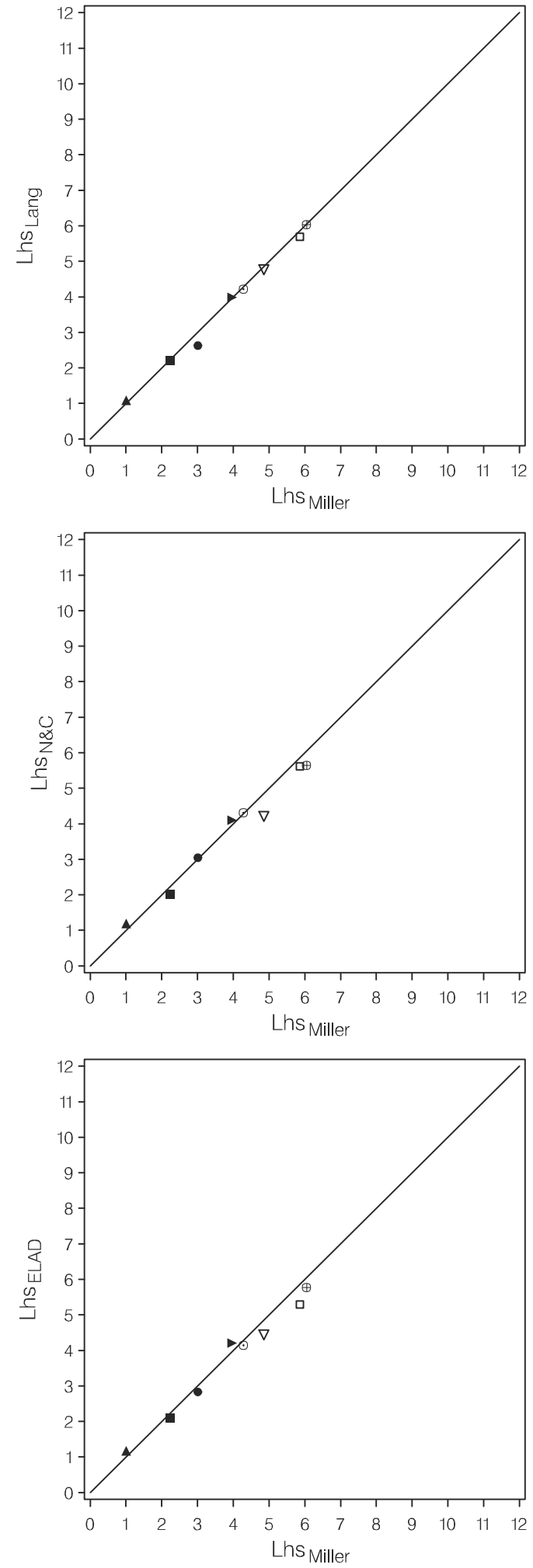

$0<$ angle $<90 \quad \Delta$ angle $=90$

$\square$ NEU $\nabla$ NOV $\odot$ OTH $\oplus \mathrm{SCH} \quad>$ VOR

Fig. 4 continued 
(c)
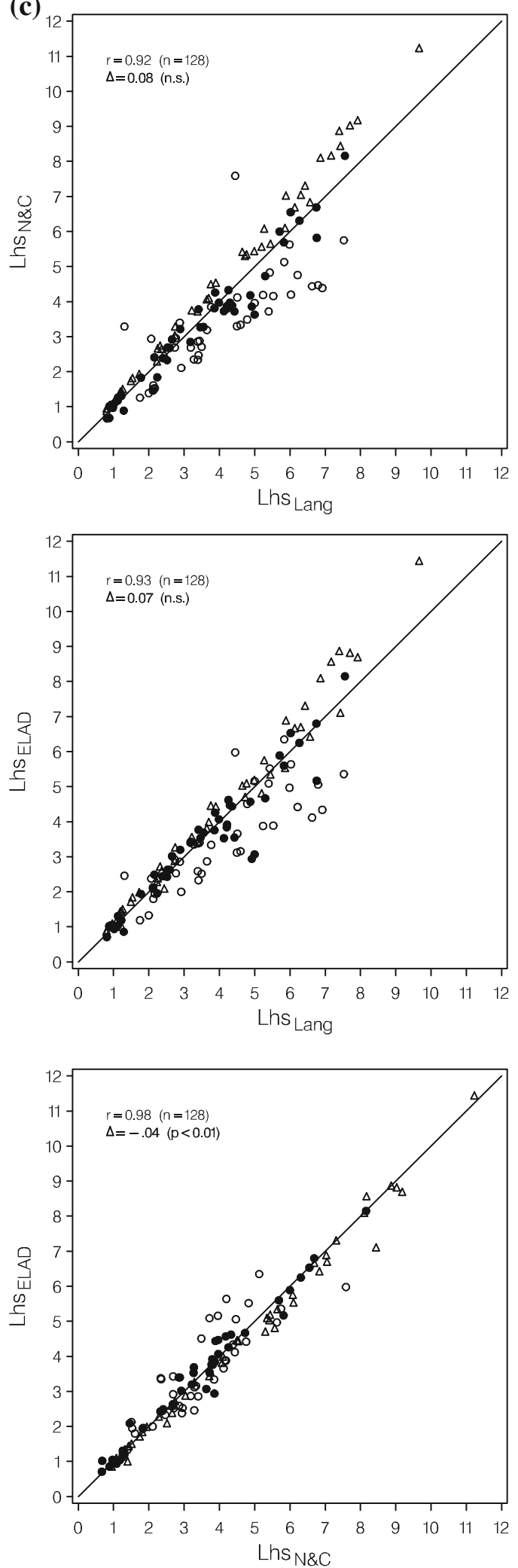

Leaf angle (left)

Site (right)

$\mathrm{O}$ angle $=0$
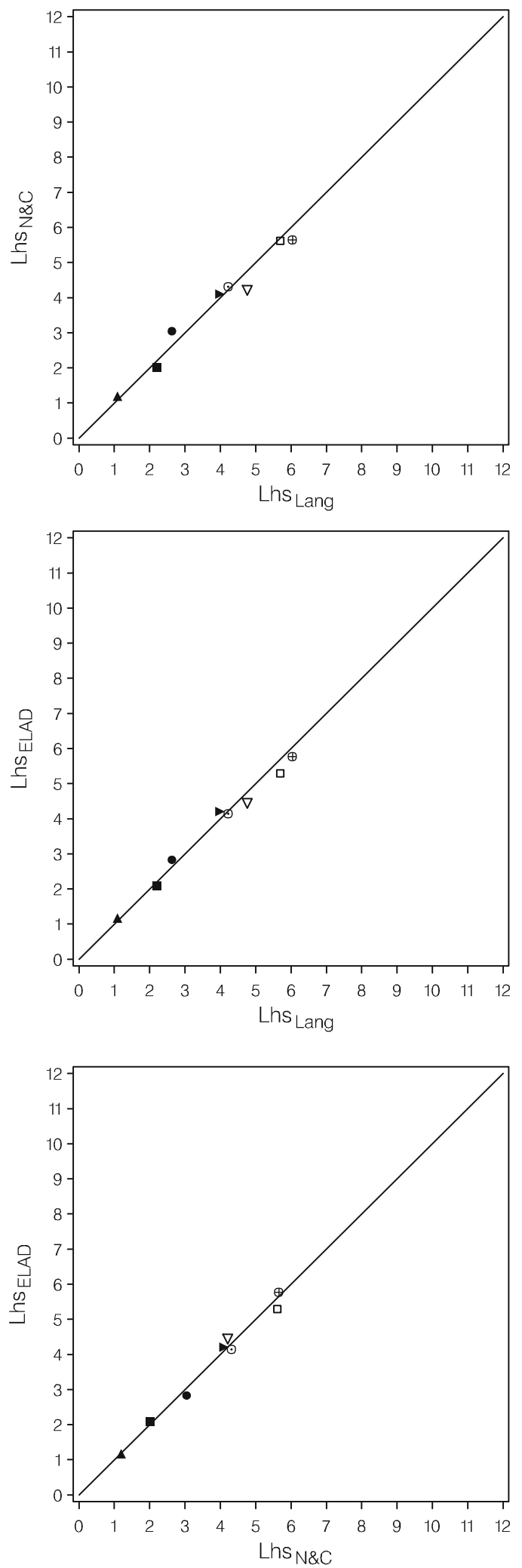

$0<$ angle $<90$

$\triangle$ angle $=90$

$\square$ NEU $\nabla \mathrm{NOV} \odot$ OTH $\oplus \mathrm{SCH}$

VOR

Fig. 4 continued 
Table 2 Differences between models with the same technique used (LAI-2000 or hemispherical photographs analysed with Hemisfer)

\begin{tabular}{|c|c|c|c|c|c|}
\hline & $n$ & Min & Max & Median & Sign test \\
\hline \multicolumn{6}{|l|}{ LAI-2000 } \\
\hline L2000 $_{\text {Lang- }}$ L2000 Miiier & 127 & -2.82 & +3.51 & -0.43 & $\mathrm{P}<0.01$ \\
\hline L2000 N\&C_L2000 Miiier & 127 & -2.31 & +2.51 & -0.61 & $\mathrm{P}<0.01$ \\
\hline L2000 N\&C-L2000 Lang & 127 & -1.63 & +1.99 & -0.17 & $\mathrm{P}<0.001$ \\
\hline \multicolumn{6}{|c|}{ Hemispherical photographs analysed with Hemisfer $(\gamma=2.2$, exposure $M+2)$} \\
\hline Lhs $_{\text {Lang }}-$ Lhs $_{\text {Miller }}$ & 128 & -3.75 & +1.39 & -0.02 & n.s. \\
\hline Lhs $_{\text {ELAD-Lhs }}$ Miller & 128 & -3.03 & +3.17 & +0.02 & n.s. \\
\hline $\mathrm{Lhs}_{\mathrm{N} \& \mathrm{C}^{-}}-\mathrm{Lhs}_{\text {Miller }}$ & 128 & -2.64 & +2.96 & -0.02 & n.s. \\
\hline $\mathrm{Lhs}_{\mathrm{N} \& \mathrm{C}}-\mathrm{Lhs}_{\text {Lang }}$ & 128 & -2.53 & +3.14 & +0.08 & n.s. \\
\hline $\operatorname{Lhs}_{\text {ELAD }}-$ Lhs $_{\text {Lang }}$ & 128 & -2.58 & +1.78 & +0.07 & n.s. \\
\hline $\mathrm{Lhs}_{\mathrm{ELAD}}-\mathrm{Lhs}_{\mathrm{N} \& \mathrm{C}}$ & 128 & -1.61 & +1.44 & -0.05 & $\mathrm{P}<0.01$ \\
\hline
\end{tabular}

All LAI values are calculated with 3 rings

could be as large as 3.5. On average, Miller's equation produced significantly higher estimates than Lang's equa-

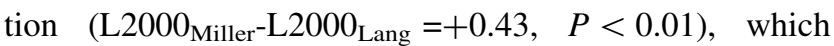
itself resulted in significantly higher estimates than Norman and Campbell's model $\left(\mathrm{L}^{2000_{\mathrm{N} \& \mathrm{C}}-\mathrm{L} 2000_{\text {Lang }}}=-0.17\right.$, $P<0.001$; Table 2).

With Hemisfer, the differences between the estimates derived from the various equations were not significant, except between the ELAD method and Norman and Campbell's solution. These two latter methods showed the

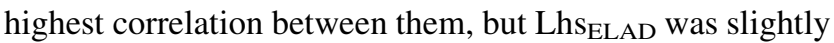
lower than $\mathrm{Lhs}_{\mathrm{N} \& \mathrm{C}}(-0.05, P<0.01$ for $\gamma 2.2$, Table 2).

Compared to the other methods, Miller's equation tended to produce higher LAI estimates when the mean foliar angle was estimated to be $0^{\circ}$ (horizontal leaves), and lower estimates when the mean foliar angle was $90^{\circ}$ (erect leaves) (Fig. 4). In this method, the leaf angle is estimated after the calculation of LAI, while the ELAD or Norman \& Campbell's method is based on a joint estimation of both LAI and leaf angle. Nevertheless, an extreme value of the leaf angle can always be considered as a symptom of problems with fitting the model to the actual measurements. This can be due to random deviations from an ideal canopy, like clumping, or to the effect of a strong slope (Montes et al. 2007; Schleppi et al. 2007). From the present study, Miller's method appears clearly less robust than the other ones for the estimation of the leaf angle, but with the advantage that it does not compromise the LAI value obtained beforehand.

\section{Comparison between sensor techniques}

Figure 5 shows the relationship between the LAI-2000 and the hemispherical photographs (2004 with P exposure only, and 2005 with $\mathrm{M}, \mathrm{M}+1, \mathrm{M}+2$ and $\mathrm{P}$ exposure) at the quadrat and at the plot level (shown here with Norman and Campbell's model). Significant correlation coefficients were obtained between estimates derived from the two techniques. Up to L2000 values of approx. 2, the best match between L2000 and Lhs was obtained with the M exposure setting, which also corresponded to the P setting. Yet the higher the LAI (L2000 estimate), the more the M setting overestimated the LAI. For L2000 between 2 and 5, the $\mathrm{M}+1$ setting seemed to be the most appropriate to achieve a satisfactory match between Lhs and L2000. Above approx. 5, Lhs with $\mathrm{M}+2$ exposure tended to compare better with L2000. Differences at the quadrat level between Lhs and L2000 tended to increase with increasing LAI values.

Lhs with the $\mathrm{P}$ exposure setting tended to level off above LAI values of 3, as occurred in both the 2004 and 2005 photographs. A plateau (around 4-5 for Norman and Campbell's model, Fig. 5; 3-4 for Miller or Lang's model, not shown) was even more obvious with the 2004 photographs, as the 2004 sampling set included more plots than in 2005, and thus had a wider range of L2000 LAI values. Moreover, the $\mathrm{P}$ photographs taken in 2005 at NEU under dark conditions (see Fig. 2) resulted in higher LAI values, closer to the L2000 values than the other P photographs taken in closed canopies.

\section{Blooming effect}

Holes in the reference grid (1250 holes, all uncovered) were correctly represented on a picture taken with automatic exposure (P). After automatic thresholding, the light transmission obtained (30\%) was accurate. Covering up to $99.2 \%$ of the holes, the light transmission should have been reduced to $0.24 \%$. In automatic exposure, however, the few open holes expanded to almost 3 times their diameter and the light transmission did not decrease below $1.8 \%$ 

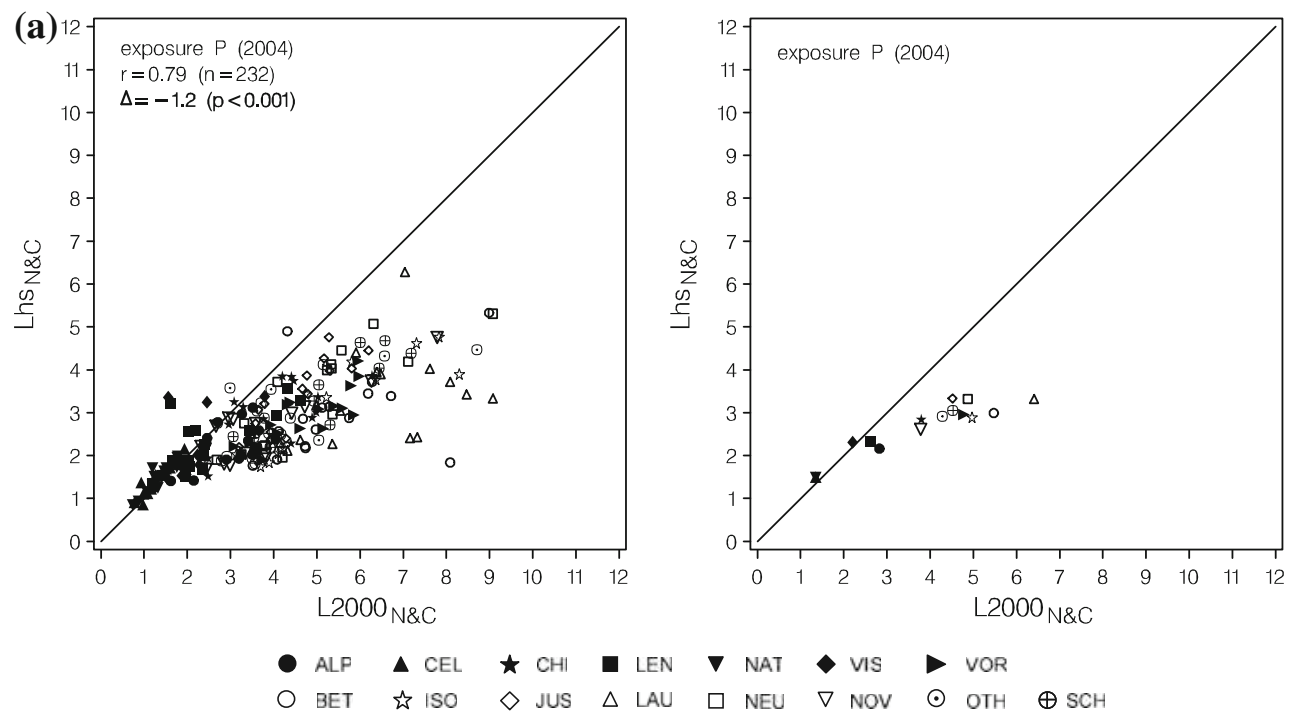

$\bigcirc$ BET 出 ISO $\diamond$ JUS $\triangle$ LAU

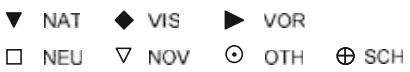
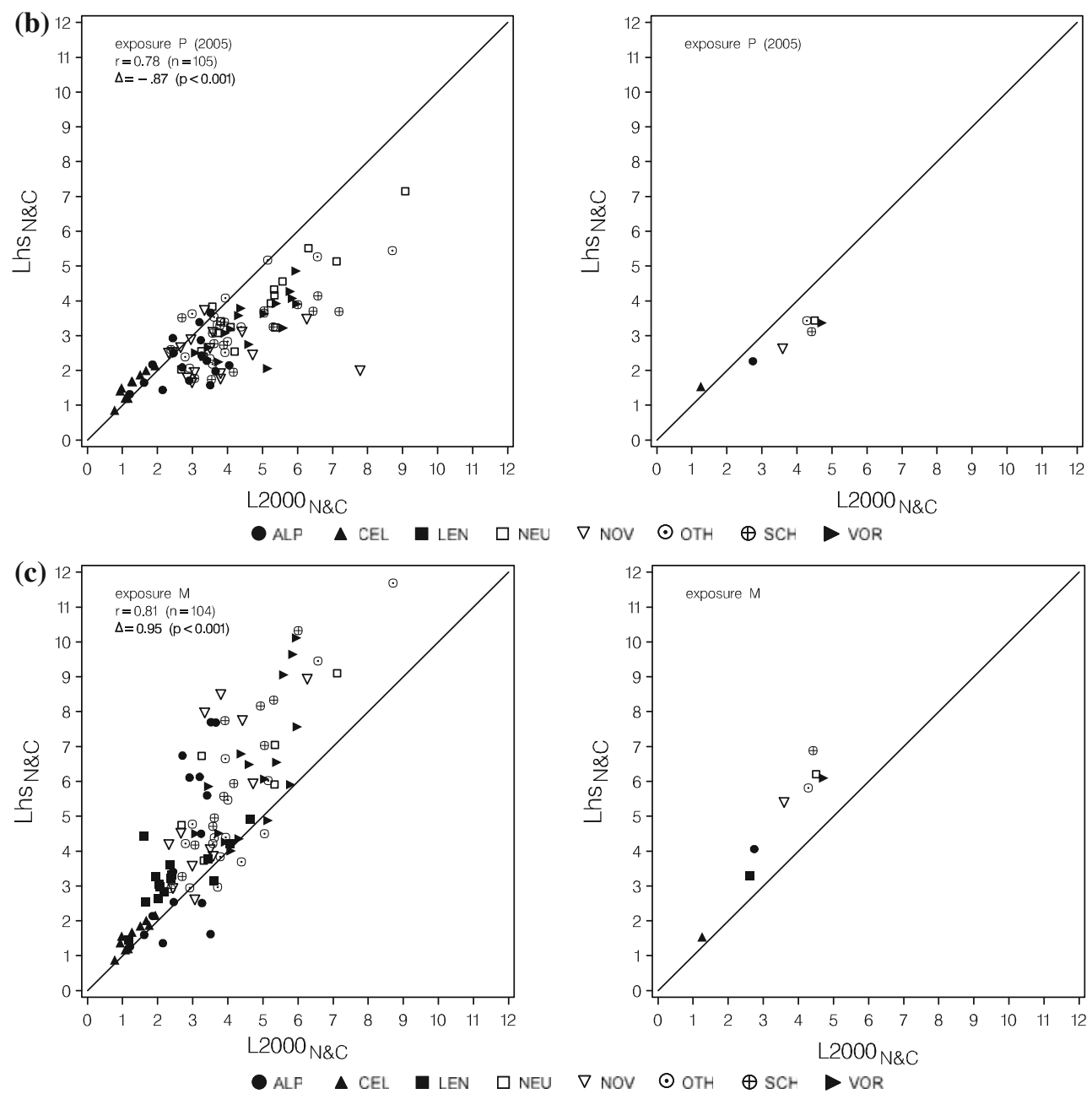

Fig. 5 Comparison of techniques with the same model equation (Norman and Campbell) used. On the left: LAI per quadrat; on the right: LAI per site. Filled symbols: coniferous stands; open symbols:

deciduous stands. a 2004, exposure P. b 2005, exposure P. c 2005, exposure M. d 2005, exposure $M+1$. e 2005, exposure $M+2$ 

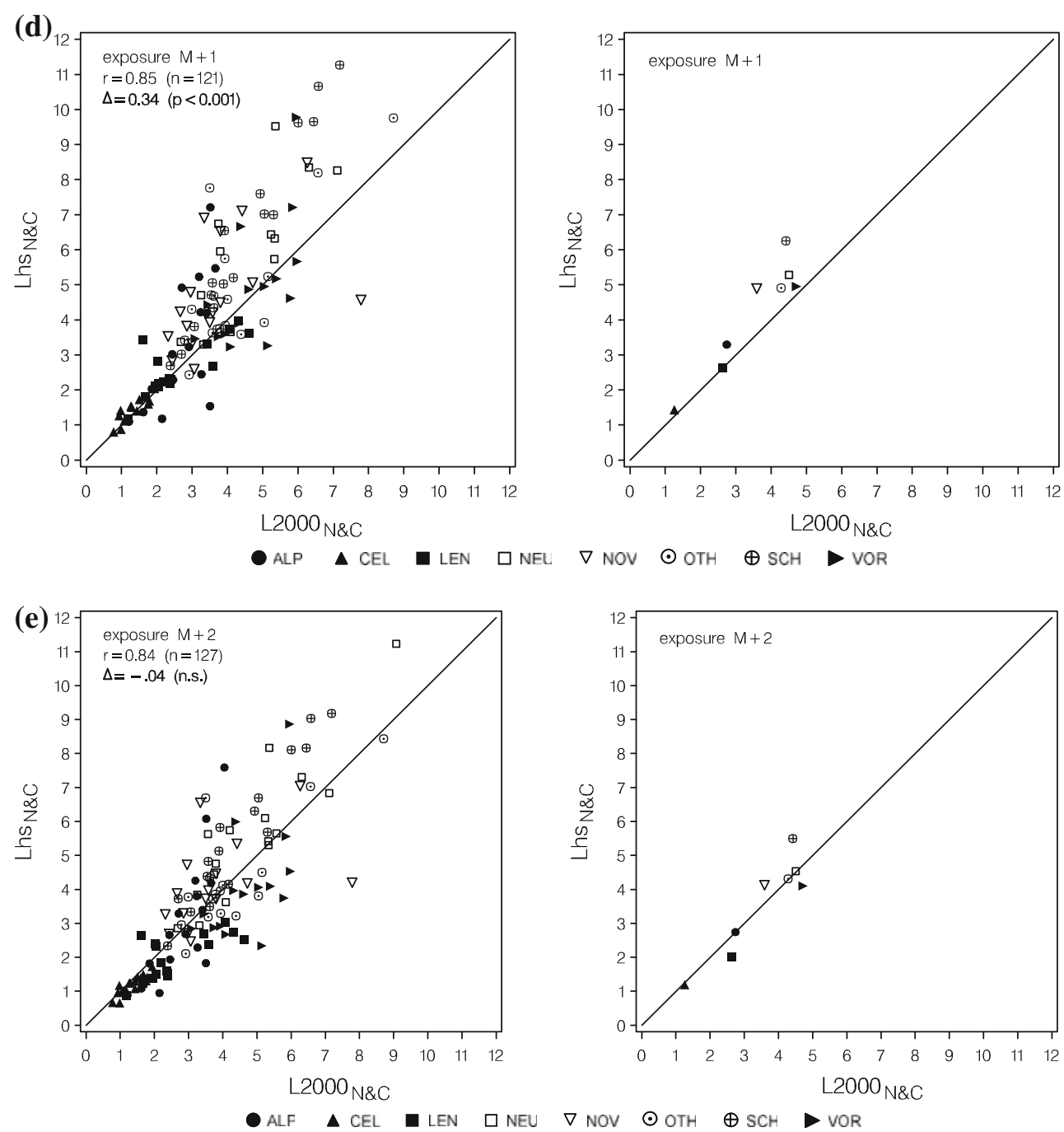

Fig. 5 continued

(Fig. 6). In terms of LAI, this would mean an estimate of 4 instead of 6 . The blooming effect was prevented by manually keeping the same exposure as that measured for the uncovered grid.

Comparison of indirect methods and the litterfall method

The cumulative dry mass of collected leaves, the specific leaf area (SLA) and the partial LAI per plot and tree species category are given in Table 3 . The lowest values of SLA were obtained for oak leaves (119 to $131 \mathrm{~cm}^{2} \mathrm{~g}^{-1}$ ), while the highest value of SLA was measured on hornbeam leaves $\left(255 \mathrm{~cm}^{2} \mathrm{~g}^{-1}\right.$ at JUS). For the same species, SLA could vary markedly: for beech leaves, SLA ranged from 195 (at OTH) to $247 \mathrm{~cm}^{2} \mathrm{~g}^{-1}$ (at SCH). These SLA values are in the range of values obtained by other authors (e.g. Bréda 2003).
The indirect techniques and the litterfall method cannot be compared at the sampling point level, since the location of the litterfall traps differs from the location of the vegetation quadrats where the LAI-2000 measurements were made and hemispherical photographs taken. In addition, the area sampled by litterfall traps is not clearly delimited in space due to the effect of wind. The direct and indirect methods were thus compared at the plot level (Table 4).

There was no clear relationship between the LAI estimates derived from litterfall (Llit) and the uncorrected estimates from the LAI-2000 (L2000) (Fig. 7a) or from the 2005 hemispherical photographs (exposure setting $\mathrm{M}+2$ ) analysed with Hemisfer (Lhs). Selecting only the subset of quadrats and litterfall traps located next to each other $(<4 \mathrm{~m})$ did not improve the relationship (results not shown).

The litterfall estimates covered a broader range of LAI (2.9 to 7.8 ) than the estimates derived from the LAI-2000. 
Fig. 6 Blooming effect: grid with 1250 round holes photographed with automatic exposure. Left: all holes open (30\% of the surface area). Right: 10 holes open (in reality $0.24 \%$ of the surface area)

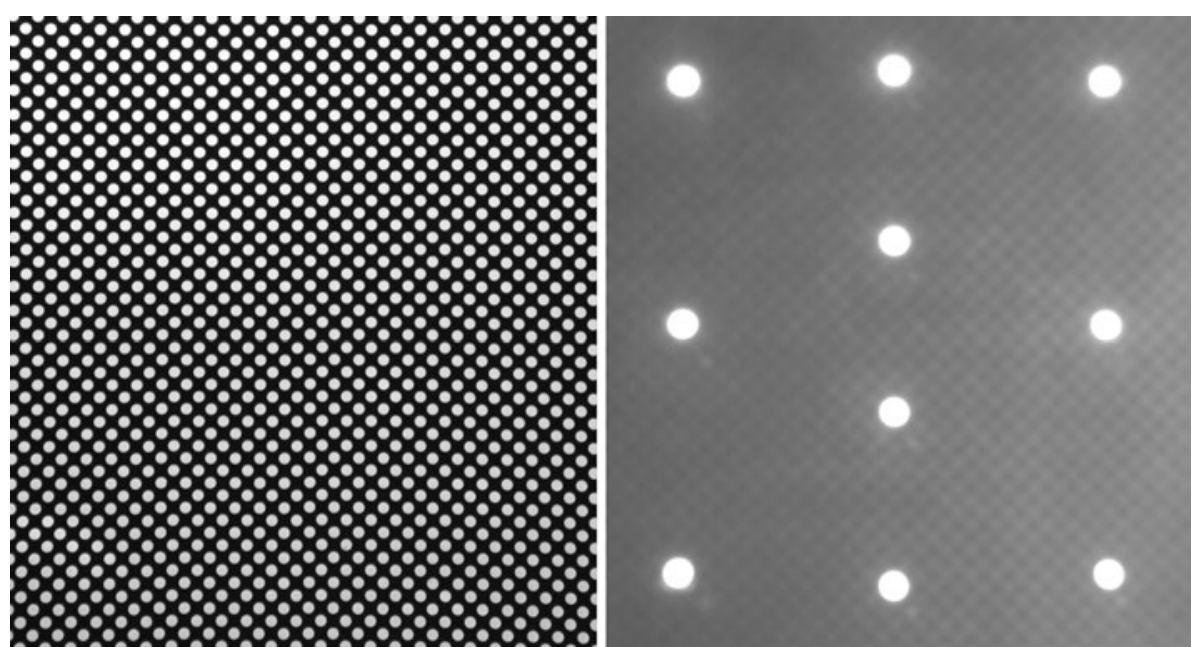

Table 3 Litterfall mass, SLA and partial LAI on sites with predominately deciduous species

\begin{tabular}{|c|c|c|c|c|c|}
\hline Site & Date & Species category & $\begin{array}{l}\text { Litterfall } \\
\text { mass }\left(\mathrm{g} / \mathrm{m}^{2}\right)\end{array}$ & $\begin{array}{l}\text { SLA } \\
\left(\mathrm{cm}^{2} / \mathrm{g}\right)\end{array}$ & $\begin{array}{l}\text { Partial LAI (per } \\
\text { species category) }\end{array}$ \\
\hline \multirow[t]{4}{*}{ JUS } & \multirow[t]{4}{*}{$24.08 .04-15.11 .04$} & Quercus robur \& Q. petraea & 109.9 & 119.1 & 1.3 \\
\hline & & Carpinus betulus-leaves & 99.4 & 254.8 & 2.5 \\
\hline & & Carpinus betulus-fruits & 84.7 & 54.8 & 0.5 \\
\hline & & Acer campestre, Populus tremula, Fagus sylvatica & 2.6 & 210.6 & 0.1 \\
\hline \multirow[t]{2}{*}{ NOV } & \multirow[t]{2}{*}{$21.09 .04-14.11 .04$} & Quercus cerris \& $Q$. pubescens & 336.7 & 123.4 & 4.2 \\
\hline & & $\begin{array}{l}\text { Corylus avellana, Sorbus aria, Castanea sativa, } \\
\text { Betula pendula }\end{array}$ & 30.6 & 201.6 & 0.6 \\
\hline \multirow[t]{2}{*}{ BET } & \multirow[t]{2}{*}{ 21.09.04-30.11.04 } & Fagus sylvatica & 174.4 & 213.7 & 3.7 \\
\hline & & $\begin{array}{l}\text { Acer pseudoplatanus, Ulmus glabra, } \\
\text { Fraxinus excelsior }\end{array}$ & 26.2 & 160.8 & 0.4 \\
\hline LAU & 07.09.04-10.01.05 & Fagus sylvatica & 327.9 & 230.4 & 7.6 \\
\hline \multirow[t]{2}{*}{ NEU } & \multirow[t]{2}{*}{ 23.08.04-28.12.04 } & Fagus sylvatica & 293.9 & 212.7 & 6.3 \\
\hline & & Tilia platyphyllos, Acer sp., Fraxinus excelsior & 27.9 & 213.5 & 0.6 \\
\hline \multirow[t]{2}{*}{ OTH } & \multirow[t]{2}{*}{ 23.08.04-28.12.04 } & Fagus sylvatica & 399.9 & 194.7 & 7.8 \\
\hline & & Quercus petraea \& $Q$. robur & 3.5 & 131.1 & $<0.1$ \\
\hline \multirow[t]{2}{*}{$\mathrm{SCH}$} & \multirow[t]{2}{*}{$08.10 .04-07.12 .04$} & Fagus sylvatica & 92.8 & 247.5 & 2.3 \\
\hline & & Acer pseudoplatanus, Fraxinus excelsior & 34.3 & 187.8 & 0.6 \\
\hline
\end{tabular}

The standard error of Llit was also larger than that of L2000. Because Miller's, Lang's and Norman and Campbell's methods produce significantly different LAI estimates when applied in the LAI-2000 software, the differences between Llit and L2000 tended either to be reduced or to increase depending on the plot and the model. Whatever the model equation, however, Llit was much lower than L2000 at BET and SCH and much higher than L2000 at OTH.

Correcting L2000 and Lhs for clumping and slope effects slightly improved the relationship between the indirect and semi-direct methods (Fig. 7b), but the correlation coefficient was still not significant. L2000 and Lhs at
OTH remained lower than Llit, while L2000 and Lhs at $\mathrm{SCH}$ and BET remained higher than Llit.

\section{Discussion}

Hemispherical photographs compared with LAI-2000

In our comparative study, we found a strong relationship between the LAI estimates from the LAI-2000 and from hemispherical photographs. Similar relationships have been reported in the majority of published studies in different forest types, e.g. Chen et al. (1997) in boreal forests, 


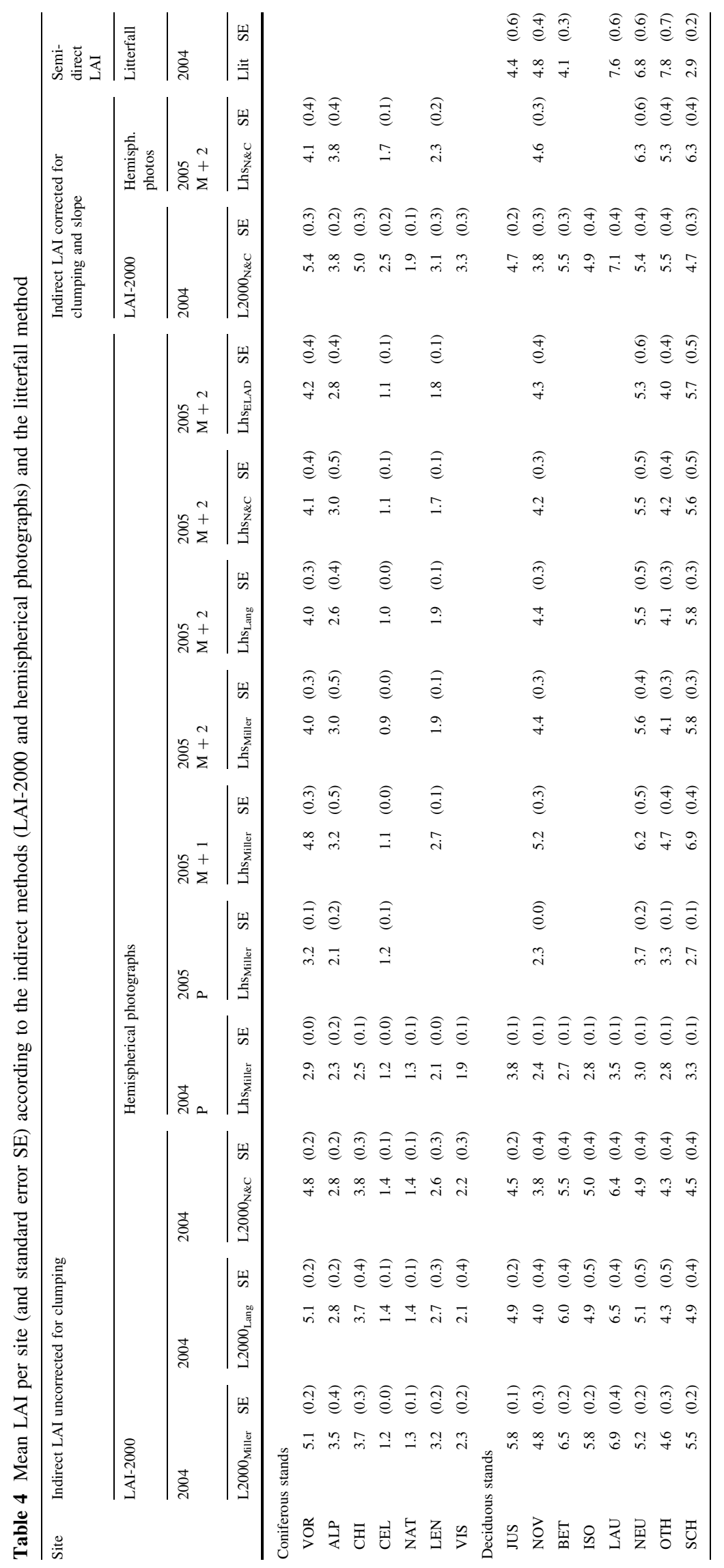


Coops et al. (2004) in natural eucalyptus forests, Frazer et al. (2000) in Douglas-fir and western hemlock stands, Macfarlane et al. (2000) in an Eucalyptus plantation and Martens et al. (1993) in a mixed conifer forest.

Some researchers report a tendency for hemispherical photographs to underestimate LAI compared with the LAI2000 (Coops et al. (2004); Ferment et al. (2001); Frazer et al. (2000); and Mussche et al. (2001), in oak-beech and ash stands). Others have found higher LAI estimates from
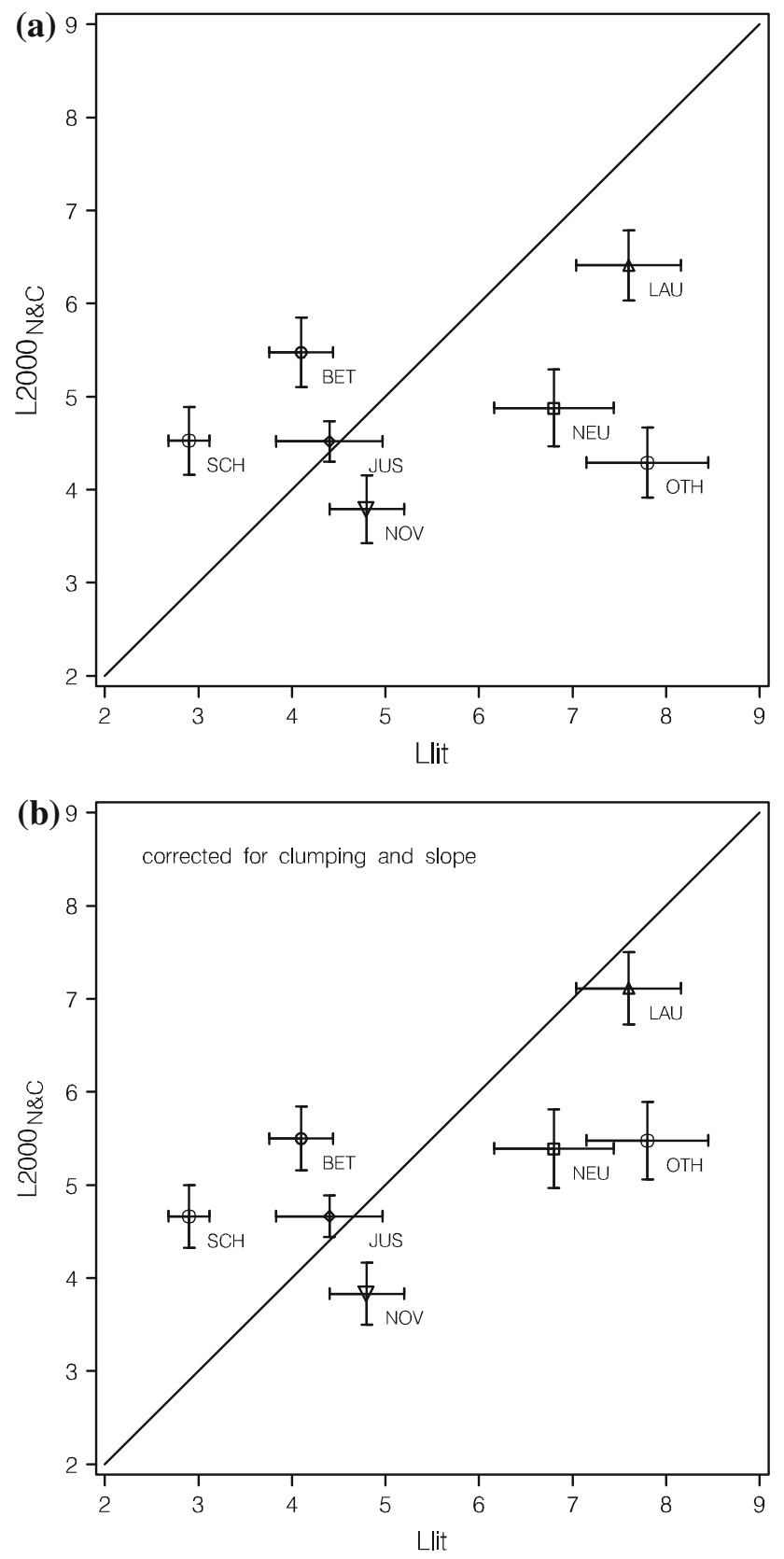

Fig. 7 Comparison of the litterfall and the LAI-2000 estimates (Norman and Campbell's equation). a Uncorrected L2000 estimates. b L2000 estimates corrected for clumping and slope. Bars indicate the standard errors hemispherical photographs in forests in the lower range of LAI (L2000 < 3.5; Martens et al. 1993, in an orchard; Soudani et al. 2001, in an oak-beech stand). Close or reasonably close matches between the two LAI estimates have also been observed (Chen et al. 1997; Planchais and Pontailler 1999; Strachan and McCaughey 1996, in heterogeneous deciduous forests; Wang et al. 1992, in an oak forest).

The lack of a systematic pattern in these studies is partly due to the variety of conditions under which they have been carried out. Factors that differ include the type of forest and its degree of homogeneity, the use of view caps or the exclusion of one or more rings with the LAI-2000, the use of digital or film photography, the exposure and the thresholding of hemispherical photographs, the partitioning of the hemispherical photographs into zenithal and azimuthal sectors when calculating the gap fraction, and the model describing the interception of radiation within the canopy layers.

Digital photography has been shown to provide higher estimates of canopy openness than film photography (Englund et al. 2000; Frazer et al. 2001; Nobis and Hunziker 2005). Significant differences have also been found between two different digital cameras equipped with the same lens (Inoue et al. 2004). Frazer et al. (2001) particularly complained about some colour blurring on their photographs. Leblanc et al. (2005) noted that light saturation on the sensor causes a blooming of white patches. This effect arises when too many photons reach a pixel on the sensor of the digital camera; their electronic excitation then spills over onto neighbouring pixels (Nikon customer support, pers. comm.). On the sensor, the red, green and blue pixels are set beside each other (at least in our camera and all those used in the publications cited). To produce conventional file formats, the raw readings are converted to bring all three colour values into single pixels. The hardware and software for this conversion vary depending on the camera model and this affects the resulting pictures. The conversion process is designed to reduce the blooming effect, but it never fully suppresses it. We could demonstrate this by progressively covering holes on a grid held against the light. In automatic exposure, the diameter of the holes increased as their number decreased. This blooming resulted in a strong underestimation of the LAI values, with a theoretical value of 6 giving only a reading of 4 . This bias is comparable with the difference observed between LAI-2000 and hemispherical photography using automatic exposure. The underestimation of LAI from photographs taken in automatic mode is thus largely explained by the blooming effect.

The blooming of white patches on dark pictures can be avoided only by underexposing the photographs in canopies with an effective LAI larger than 2. From a theoretical point 
of view, this underexposure should amount to $\mathrm{e} / 2 \approx 11 / 3$ exposure stops per unit LAI. The importance of a correct exposure setting has been already stressed in several publications (Chen et al. 1991; Zhang et al. 2005). The method of using a spotmeter pointed at a small gap to measure the sky brightness in order to select the optimum exposure setting has already been used by e.g. Becker (1971). It has the advantage of not needing measurements outside the forest stand, unlike the method proposed by Zhang et al. (2005). These authors recommend determining a reference exposure in an open area and then overexposing the photographs in the stand by two stops relative to the reference exposure. This method is more time-consuming. It may require corrections using reference exposures at the beginning and end of the measurements, as sky brightness can change quite fast, especially at sunrise or sunset (Chen et al. 2006).

In their standard setting, many digital cameras apply a software filter to sharpen the picture. This filter should be turned off because it can also introduce small errors. When we applied a similar filter after image acquisition, we found no difference below LAI $=2.5$, but at higher values it resulted in the calculated LAI being biased by $-0.06 \pm 0.07$.

Introducing a $\gamma$ correction in the calculation of the threshold increases the number of black pixels in the photographs, giving lower transmittances and thus higher LAI estimates (by $10 \%$ on average). The correction was found to be stronger at higher LAI, and it has a greater influence where the canopy structure is homogeneous, as is the case at NOV (Fig. 1). Homogeneous canopies result in photographs with few large gaps and many smaller gaps, which enhances border effects. Subjectively, the black and white pictures obtained with a $\gamma$-corrected threshold appeared too dark, while the uncorrected threshold seemed better. Nobis and Hunziker (2005) found a good agreement between a $\gamma$-uncorrected automatic threshold and the average of thresholds set manually by different people. It must be remembered, however, that the $\gamma$ transformation of the camera is introduced with the purpose of adapting the light curve to the human eye. This can explain why an uncorrected threshold can appear better than a $\gamma$-corrected one, even though the latter is theoretically superior for analysing the physical properties of the picture.

Hemispherical photographs and LAI-2000 compared with the litterfall method

The litterfall method, applied in seven broadleaved stands, produced LAI estimates ranging from 2.9 to 7.8 . The litterfall estimates correlated neither with the LAI-2000 nor with the photograph estimates. This lack of correlation could be partly related to the small number of stands included in the comparison (seven plots), which makes it sensitive to outliers.
Due to the limited number of measurement points, the standard errors were relatively large, especially for the litterfall method. This variability, however, is not sufficient to explain the discrepancies between the two techniques, as shown in Fig. 7. At OTH, the litterfall estimate (7.8) was considerably higher than the (uncorrected) LAI-2000 estimate (4.3 to 4.6 depending on the model). LAI-2000 measurements, carried out in summer 2001 above the same 16 vegetation quadrats, produced a much higher average value: 7.8 (Miller's equation). In June 2002, several large trees were blown down by a storm, which could explain the decrease in LAI as estimated with the LAI-2000. Visual comparison of the hemispherical photographs made in 2001 and 2004 confirms the increase in canopy gaps between the two sampling dates. Moreover, a repetition of LAI-2000 measurements on 2 July 2004 (data not shown) confirmed the LAI estimates obtained from the measurements on 30 June, which excludes the hypothesis of incorrect measurements on this date. Litterfall data, collected in 1998 using a set of 5 traps (most of them different from the ones used in 2004), gave an LAI estimate of 7.5, quite close to the 2004 estimate. The litterfall method thus does not reflect the decrease in LAI expected from storm damage and assessed by the LAI-2000 measurements. In heterogeneous stands, such as stands locally damaged by windthrow, the number of litterfall traps is critical, as a trap samples only a limited area (the crown directly above it, in the absence of wind). In contrast, the spatial range of the LAI-2000 approximately equals the canopy height when the three inner rings are used. On the other hand, the LAI2000 may have emphasized the decrease in LAI due to windthrow, as the underestimation with the LAI-2000 compared with direct methods, reported in several studies in the literature, is usually clearer for heterogeneous stands (e.g. Mussche et al. 2001). This is especially the case when no view caps are used during measurements, as was the case in our study. Canopy gaps are then over-weighted when the gap fraction is linearly averaged over the azimuth. However, this bias is overcome when LAI-2000 estimates are corrected for clumping by applying factors derived from hemispherical photographs, as in Fig. 7b.

At $\mathrm{SCH}$ and BET, the litterfall estimate was lower than the LAI-2000 estimate by approx. 2.5 units. At BET, the stand is composed not only of Fagus sylvatica but also of coniferous species such as Abies alba and Picea abies, whose contribution is not taken into account in the litterfall method. In addition, litterfall collection had to be stopped in 2004 before snowfall and not all leaves in the tree crowns could be collected on these two plots. In 2005, litterfall was collected throughout the winter at both $\mathrm{SCH}$ and BET. At BET, $<10 \%$ more litterfall was collected in 2005 than in 2004, but at $\mathrm{SCH}$, the relative difference was about $50 \%$ between 2004 and 2005. However, Llit, roughly 
estimated with the 2005 litterfall amount, together with the SLA determined in 2004, still remains markedly lower than L2000 at SCH. Even in the absence of disturbances (such as windthrow or thinning), the production of foliage, and thus the LAI of the stand, can vary from year to year due to climatic factors (e.g. Graf Pannatier et al. 2007). The litterfall production in 2005 may thus not be representative for 2004. Another plausible explanation for the lack of agreement between litterfall and LAI-2000 estimates might be related to strong winds on the site, due to the topography around the plot, which would negatively bias the collection of falling leaves.

\section{Conclusion}

Hemispherical photography is potentially promising for estimating LAI because, unlike the LAI-2000, it offers a permanent record of the structure of the canopy, allowing the visualization of the distribution and size of the canopy gaps. Thus, any clumping on the canopy scale (resulting in the occurrence of large gaps) can be corrected for. On sloped terrains, the ground is visible on the photograph. Slope and aspect can be recorded and their effect can be taken into account when estimating LAI. The Hemisfer software used in this study offers both these corrections, i.e. for canopy clumping and slope. Compared with the LAI-2000, further advantages of the photography technique are that it does not require reference measurements, and that it can be applied under a wider range of sky conditions, for example, when the sky is brighter in one direction. Scattered clouds are still, however, a problem.

The difference between the time required for the photography technique and that for the LAI-2000 technique has been considerably reduced by the development of high resolution digital photography, which allows the cumbersome step of digitizing pictures obtained with film photography to be bypassed. Automatic thresholding of the photographs helps to save time and to avoid the subjectivity of manual thresholding. We have also been able to show that automatic thresholding, implemented with the appropriate function for transforming back computer-coded brightness values of the photograph into physical light intensity (gamma correction), gives better results than manual thresholding. However, automatic thresholding does not allow any correction of the effects of wrong exposure, which leaves the LAI estimation sensitive to the exposure of the pictures. Selecting appropriate exposure settings is therefore essential, especially in forest stands with LAI > 3 (see Fig. 3). Overexposing the photographs by one to two stops relative to the exposure determined manually with a spotmeter in a gap provides satisfactory results. In comparison, the LAI-2000 has the advantage of being faster, both in the measuring and the processing steps. It also offers a satisfactory reproducibility of the measurements, but only as long as these are done under more-or-less homogeneous sky conditions. We show here how LAI-2000 measurements can be iteratively corrected for the effect of the slope.

The estimates obtained from the indirect techniques, LAI-2000 and hemispherical photography, did not match on all plots the semi-direct measurements through litterfall sampling in our broadleaved stands. The sampling strategies for litterfall sampling and LAI-2000 measurements were designed separately and were not intended, initially, to allow comparative exercises. This might partly explain the lack of relationship between the two estimates. An independent, accurate measure of the true LAI is lacking, which makes it difficult to draw conclusions about which technique and which equation gives the best estimate. Further investigations of the temporal and spatial variation would help interpret the differences observed between the LAI estimates obtained with the different methods. The plausibility of the LAI estimates could be tested by repeating LAI measurements (LAI-2000 or photographs) over the year in order to check whether the temporal pattern obtained is coherent with the stand phenology, (with an increase in LAI from spring to summer and a decrease in the autumn in broadleaved stands) and, if available, with continuous radiation measurements taken above and below the canopy. The reproducibility of the method should be tested by repeating LAI measurements at intervals of a few days, when maximum LAI is reached, under different conditions (overcast sky, before sunrise and after sunset). Repeating LAI measurements at the same locations immediately after a first series of measurements also helps to detect possible biases due to changing light conditions.

Acknowledgments We are very grateful to A. Brechbühl, N. Hajjar, O. Schramm, D. Trummer and the staff from the forest services for collecting the litterfall samples on the LWF plots. A. Brechbühl also participated in sorting the litterfall samples. We warmly thank O. Schramm and P. Waldner for their participation in the field campaign 2005. We also thank M. Nobis for his technical advice on the analysis of hemispherical photographs and S. Dingwall for editing the English. We gratefully acknowledge the financial support of the Federal Office for the Environment (FOEN).

\section{Appendix}

General principles and equations for estimating LAI from the gap fraction of the canopy

Indirect estimation of LAI using optical methods relies on the dependency between the canopy structure (LAI and leaf angle distribution) and the gap fraction of the canopy. 
Assuming that (1) leaves are randomly distributed within the canopy, (2) leaves do not transmit any light and (3) individual leaf size is small compared with the canopy, the gap fraction is equivalent to the transmittance as measured with the LAI-2000. In the case of hemispherical photographs, the gap fraction is directly determined on the photograph from the proportion of visible sky. In a horizontally homogeneous canopy with randomly distributed leaves, the mean transmittance or gap fraction at solar zenith angle $\theta, T(\theta)$, is given by the Poisson probability density function (Nilson 1971):

$T(\theta)=e^{-\frac{G(\theta) L}{\cos \theta}}$

where $L=$ one-sided leaf area index $=$ one-sided leaf area per ground area, $G(\theta)=$ ratio between the projected and one-sided leaf area when projected in direction $\theta$ (azimuthal average). $G(\theta)$ is a function of both $\theta$ and the leaf angle distribution (i.e. the distribution of inclination and azimuth angles of leaves).

Equation (A.1) is analogous to the Beer-Lambert law describing the attenuation of the radiation with distance inside the canopy:

$T(\theta)=e^{-k \cdot L}$

where $k=$ extinction coefficient.

By inverting equation (A.1):

$G(\theta) L=-\ln [T(\theta)] \cos \theta=K(\theta)$

$K(\theta)$ is called the contact frequency. It represents the average number of contacts per unit length of travel that a probe would make by passing through the canopy at zenith angle $\theta$.

When measurements are integrated from zenith to horizon $(0 \leq \theta \leq \pi / 2)$, the effect of the leaf angle distribution disappears. In this case, Miller (1967) showed that $L$ is related to $K$ as:

$L=2 \int_{0}^{\pi / 2} K(\theta) \sin \theta d \theta$

The Li-Cor software calculates LAI using a discrete version of Miller's (1967) integration:

$L=2 \sum_{i=1}^{5} K\left(\theta_{i}\right) \sin \left(\theta_{i}\right) \Delta \theta_{i}$

where $\theta_{i}$ is the midpoint of ring $i, \Delta \theta_{i}$ is the angular width of ring $i$, and $K\left(\theta_{i}\right)$ are the contact frequencies obtained from the transmittances $T\left(\theta_{i}\right)$ calculated for each pair of above- and below-canopy readings (see A.2).

With $W_{i}=\sin \left(\theta_{i}\right) \cdot \Delta \theta_{i}$, equation (A. $\left.3^{\prime}\right)$ becomes:

$L=2 \sum_{i=1}^{5} K\left(\theta_{i}\right) \cdot W_{i}$ where $W_{i}$ (with $i=1$ to 5) are the weighting factors related to each ring, namely $0.034,0.104,0.160,0.218$ and 0.484 . The largest weight affects the 5th ring, which measures only up to $74^{\circ}$, but its measurements are used in the integration up to $90^{\circ}$. If the 5th and 4 th rings are skipped, their weight is added to the third ring.

Transmission measurements close to the horizon are often less precise, and sometimes even impossible because of the limited plot size or the topography. For this reason, Lang $(1987,1986)$ proposed estimating $L$ from $K(1 \mathrm{rad})$ because the effect of the leaf angle distribution is minimal at $\theta=1 \mathrm{rad}$, with $G(\theta) \approx 0.5$. Lang estimated $K(1 \mathrm{rad})$ by calculating a linear regression of $K$ against $\theta$ :

$K=a+b \theta$

By substituting equation (A.4) into equation (A.3) and integrating, Lang (1987) expressed LAI as:

$L=2(a+b)$

A last method of estimating LAI from equation (A.1) relies on further assumptions concerning the leaf angle distribution of the canopy. Campbell (1986) derived an equation for the extinction coefficient of canopy elements distributed in the same proportions and orientation as the surface of an ellipsoid of revolution, symmetrically around a vertical axis. If the vertical semi-axis is a and the horizontal semi-axis $\mathrm{b}$, the ellipsoidal leaf angle distribution parameter (ELADP) is defined as $x=b / a$. The extinction coefficient $\mathrm{k}$ for light penetrating a canopy of ELADP $x$ at zenith angle $\theta$ is approximated by (Campbell 1986):

$k=\frac{G(\theta, x)}{\cos \theta}=\frac{\sqrt{x^{2}+\tan (\theta)^{2}}}{x+1.702 \cdot(x+1.12)^{-0.708}}$

The predicted gap fraction at zenith angle $\theta$ for a canopy with an LAI of $L$, and an ELADP of $x$ is then obtained from equation (A.1).

Norman and Campbell (1989) proposed an algorithm to solve the ellipsoidal model. In their method, the sum of squared errors between the measured and predicted logarithms of transmission $(\ln T)$ is minimized, with each ring weighted equally. A slightly different method (Schleppi et al. 2007) consists of optimizing (also by using a leastsquare approach) the contact frequencies $(K)$ weighted by the solid angle of each ring.

\section{References}

Anderson MC (1971) Radiation and crop structure. In: Sestak Z, Catsky J, Jarvis PG (eds) Plant photosynthetic production: manual of methods. Junk, The Hague, pp 412-466

Becker M (1971) Une technique nouvelle d'utilisation des photographies hémisphériques pour la mesure du climat lumineux en forêt. Ann Sci For 28:425-442 
Bréda NJJ (2003) Ground-based measurements of leaf area index: a review of methods, instruments and current controversies. J Exp Bot 54:2403-2417

Campbell GS (1986) Extinction coefficients for radiation in plant canopies calculated using an ellipsoidal inclination angle distribution. Agric For Meteorol 36:317-321

Chason JW, Baldocchi DD, Huston MA (1991) A comparison of direct and indirect methods for estimating canopy leaf area. Agric For Meteorol 57:107-128

Chen JM, Black TA (1991) Measuring leaf area index of plant canopies with branch architecture. Agric For Meteorol 57:1-12

Chen JM, Cihlar J (1995) Quantifying the effect of canopy architecture on optical measurements of leaf area index using two gap size analysis methods. IEEE Trans Geosci Remote Sens 33:777-787

Chen JM, Black TA, Adams RS (1991) Evaluation of hemispherical photography for determining plant area index and geometry of a forest stand. Agric For Meteorol 56:129-143

Chen JM, Rich PM, Gower ST, Norman JM, Plummer S (1997) Leaf area index of boreal forests: theory, techniques, and measurements. J Geophys Res- Atmos 102:29429-29443

Chen JM, Govind A, Sonnentag O, Zhang Y, Barr A, Amiro B (2006) Leaf area index measurements at Fluxnet-Canada forest sites. Agric For Meteorol 140:257-268

Coops NC, Smith ML, Jacobsen KL, Martin M, Ollinger S (2004) Estimation of plant and leaf area index using three techniques in a mature native eucalypt canopy. Austral Ecol 29:332-341

Cutini A, Matteucci G, Scarascia MG (1998) Estimation of leaf area index with the Li-Cor LAI2000 in deciduous forests. For Ecol Manage 105:55-65

Dufrêne E, Bréda N (1995) Estimation of deciduous forest leaf area index using direct and indirect methods. Oecologia 104:156-162

Englund SR, O'Brien JJ, Clark DB (2000) Evaluation of digital and film hemispherical photography and spherical densiometry for measuring forest light environments. Can J For Res-Rev Can Rech For 30:1999-2005

Ferment A, Picard N, Gourlet-Fleury S, Baraloto C (2001) A comparison of five indirect methods for characterizing the light environment in a tropical forest. Ann For Sci 58:877-891

Frazer GW, Trofymow JA, Lertzman KP (2000) Canopy openness and leaf area in chronosequences of coastal temperate rainforests. Can J For Res-Rev Can Rech For 30:239-256

Frazer GW, Fournier RA, Trofymow JA, Hall RJ (2001) A comparison of digital and film fisheye photography for analysis of forest canopy structure and gap light transmission. Agric For Meteorol 109:249-263

Graf Pannatier E, Dobbertin M, Schmitt M, Thimonier A, Waldner P (2007) Effects of the drought 2003 on forests in Swiss Level II plots. In: Eichhorn $\mathbf{J}$ (ed), Forests in a changing environment. Results of 20 years ICP forests monitoring, Göttingen, Germany, October 25-28, 2006. Schriften aus der Forstlichen Fakultät der Universität Göttingen und der Nordwestdeutschen Forstlichen Versuchsanstalt, vol 142, pp 128-135

Holst T, Hauser S, Kirchgassner A, Matzarakis A, Mayer H, Schindler D (2004) Measuring and modelling plant area index in beech stands. Int J Biometeorol 48:192-201

Inoue A, Yamamoto K, Mizoue N, Kawahara Y (2004) Effects of image quality, size and camera type on forest light environment estimates using digital hemispherical photography. Agric For Meteorol 126:89-97

Lang ARG (1987) Simplified estimate of leaf area index from transmittance of the sun's beam. Agric For Meteorol 41:179-186

Lang ARG, Xiang Y (1986) Estimation of leaf area index from transmission of direct sunlight in discontinuous canopies. Agric For Meteorol 37:229-243
Leblanc SG, Chen JM, Fernandes R, Deering DW, Conley A (2005) Methodology comparison for canopy structure parameters extraction from digital hemispherical photography in boreal forests. Agric For Meteorol 129:187-207

Li-Cor (1992) LAI-2000 plant canopy analyzer-Operating manual. LI-COR, Inc, Lincoln

Macfarlane C, Coote M, White DA, Adams MA (2000) Photographic exposure affects indirect estimation of leaf area in plantations of Eucalyptus globulus Labill. Agric For Meteorol 100:155-168

Martens SN, Ustin SL, Rousseau RA (1993) Estimation of tree canopy leaf area index by gap fraction analysis. For Ecol Manage 61:91-108

Miller JB (1967) A formula for average foliage density. Aust J Bot 15:141-144

Montes F, Pita P, Rubio A, Cañellas I (2007) Leaf area index estimation in mountain even-aged Pinus silvestris L. stands from hemispherical photographs. Agric For Meteorol 145:215-228

Mussche S, Samson R, Nachtergale L, De Schrijver A, Lemeur R, Lust N (2001) A comparison of optical and direct methods for monitoring the seasonal dynamics of leaf area index in deciduous forests. Silva Fenn 35:373-384

Nilson T (1971) A theoretical analysis of the frequency of gaps in plant stands. Agric Meteorol 8:25-38

Nobis M (2003) Sideview 1.0-imaging software to extract vertical vegetation structure from true-colour photographs; http://www. appleco.de

Nobis M, Hunziker U (2005) Automatic thresholding for hemispherical canopy-photographs based on edge detection. Agric For Meteorol 128:243-250

Norman JM, Campbell GS (1989) Canopy structure. In: Pearcy RW, Ehleringer JR, Mooney HA, Rundel PW (eds) Plant physiological ecology: field methods and instrumentation. Chapman and Hall, London, pp 301-325

Planchais I, Pontailler JY (1999) Validity of leaf areas and angles estimated in a beech forest from analysis of gap frequencies, using hemispherical photographs and a plant canopy analyzer. Ann For Sci 56:1-10

Ross J (1981) The radiation regime and architecture of plant stands. Junk, The Hague

Running SW, Coughlan JC (1988) A general model of forest ecosystem processes for regional applications. 1. hydrologic balance, canopy gas-exchange and primary production processes. Ecol Model 42:125-154

Running SW, Gower ST (1991) Forest-BGC, a general model of forest ecosystem processes for regional applications. 2. Dynamic carbon allocation and nitrogen budgets. Tree Physiol 9:147-160

Schleppi P, Conedera M, Sedivy I, Thimonier A (2007) Correcting non-linearity and slope effects in the estimation of the leaf area index of forests from hemispherical photographs. Agric For Meteorol 144:236-242

Soudani K, Trautmann J, Walter JM (2001) Comparison of optical methods for estimating canopy openness and leaf area index in broad-leaved forests. C R Acad Sci Ser III-Sci Vie 324:381-392

Strachan IB, McCaughey JH (1996) Spatial and vertical leaf area index of a deciduous forest resolved using the LAI-2000 plant canopy analyzer. For Sci 42:176-181

Thimonier A, Schmitt M, Cherubini P, Kräuchi N (2001) Monitoring the Swiss forest: building a research platform. In: Anfodillo T, Carraro V (eds) Monitoraggio ambientale: metodologie ed applicazioni Atti del XXXVIII Corso di Cultura in Ecologia, 2001. San Vito di Cadore, Centro Studi per l'Ambiente Alpino, Università degli Studi di Padova, pp 121-134

Wang YS, Miller DR, Welles JM, Heisler GM (1992) Spatial variability of canopy foliage in an oak forest estimated with fisheye sensors. For Sci 38:854-865 
Weiss M, Baret F, Smith GJ, Jonckheere I, Coppin P (2004) Review of methods for in situ leaf area index (LAI) determination Part II. Estimation of LAI, errors and sampling. Agric For Meteorol 121:37-53
Zhang Y, Chen JM, Miller JR (2005) Determining digital hemispherical photograph exposure for leaf area index estimation. Agric For Meteorol 133:166-181 